\title{
Prognostic and Clinicopathological Correlations of Cell Cycle Marker Expressions before and after the Primary Systemic Therapy of Breast Cancer
}

\author{
Tímea Tőkés ${ }^{1}\left(\mathbb{D} \cdot\right.$ Anna-Mária Tőkés $^{2} \cdot$ Gyöngyvér Szentmártoni ${ }^{1} \cdot$ Gergö Kiszner $^{3}$ • Dorottya Mühl ${ }^{1}$. \\ Béla Ákos Molnár ${ }^{4}$ • Janina Kulka ${ }^{2} \cdot$ Tibor Krenács $^{3} \cdot$ Magdolna Dank $^{1}$
}

Received: 25 April 2019 / Accepted: 14 August 2019/ Published online: 24 August 2019

(C) The Author(s) 2019

\begin{abstract}
We aimed to analyze the expression of cell-cycle regulation markers - minichromosome maintenance protein 2 (MCM2), Ki-67, Cyclin-A and phosphohistone-H3 (PHH3) - in pre-treatment core-biopsy samples of breast carcinomas in correlation with known predictive and prognostic factors. Totally 52 core biopsy samples obtained prior to neoadjuvant therapy were analyzed. Immunohistochemistry was performed to analyze the expression of MCM2, Ki67, Cyclin A and PHH3, which were correlated with the following clinicopathological parameters: clinical TNM, tumor grade, biological subtype, the presence of tumor infiltrating lymphocytes (TIL), pathological tumor response rate to the neoadjuvant therapy and patient survival. All investigated markers showed higher expression in high grade and in triple negative tumors $(p<0.01$ and $p<0.05$, respectively). Hormone receptor negative tumors showed significantly higher expression of Ki-67 $(\mathrm{p}<0.01)$, MCM2 $(\mathrm{p}<0.01)$ and Cyclin A $(\mathrm{p}<0.01)$ than hormone receptor positive ones. Tumors with increased TIL showed significantly higher Ki-67 expression $(p=0.04)$. Pattern analysis suggested that novel cell-cycle marker-based subgrouping reveals predictive and prognostic potential. Tumors with high MCM2, Cyclin A or PHH3 expression showed significantly higher rate of pathological complete remission. Tumors with early relapse (progression-free survival $\leq 2$ years) and shortened overall survival also show a higher rate of proliferation. Our cell cycle marker (Ki-67, MCM2, Cyclin A, PHH3) based testing could identify tumors with worse prognosis, but with a favorable response to primary systemic therapy. The pattern of cell-cycle activity could also be useful for predicting early relapse, but our findings need to be further substantiated in larger patient cohorts.
\end{abstract}

Keywords Breast cancer $\cdot$ Primary systemic therapy $\cdot$ Cell cycle $\cdot$ Ki67 $\cdot$ MCM $\cdot$ Cyclin A $\cdot$ PHH3

Electronic supplementary material The online version of this article (https://doi.org/10.1007/s12253-019-00726-w) contains supplementary material, which is available to authorized users.

Tímea Tökés

timi.tokes@gmail.com; tokes.timea@med.semmelweis-univ.hu

1 Oncology Center, Semmelweis University, Tömö utca 25-29, 4th floor, Budapest H-1083, Hungary

2 2nd Department of Pathology, Semmelweis University, Üllöi út 93, Budapest H-1091, Hungary

3 1st Department of Pathology and Experimental Cancer Research, Semmelweis University, Üllői út 26, Budapest H-1085, Hungary

4 1st Department of Surgery, Semmelweis University, Üllöi út 78/A, Budapest H-1083, Hungary

$\begin{array}{ll}\begin{array}{l}\text { Abbreviations } \\ \text { ASCO/CAP }\end{array} & \begin{array}{l}\text { American Society of Clinical Oncology/ } \\ \text { College of American Pathologists } \\ \text { ductal carcinoma in situ }\end{array} \\ \text { DCIS } & \begin{array}{l}\text { estrogen receptor } \\ \text { ER }\end{array} \\ \text { FDG-PET/CT } & { }^{18} \text { F-fluorodeoxy-glucose positron emission } \\ \text { tomography and computer tomography } \\ \text { FISH } & \begin{array}{l}\text { fluorescent in situ hybridization } \\ \text { high-powered fields }\end{array} \\ \text { HPF } & \text { invasive breast carcinomas of no special type } \\ \text { IBC NST } & \text { immunohistochemistry } \\ \text { IHC } & \text { Ki-67 labeling index } \\ \text { Ki-67 LI } & \text { minichromosome maintenance protein } \\ \text { MCM2 } & \text { overall survival } \\ \text { OS } & \text { pathological complete remission } \\ \text { pCR } & \end{array}$




$\begin{array}{ll}\text { PHH3 } & \text { phosphohistone-H3 } \\ \text { PR } & \text { progesterone receptor } \\ \text { PFS } & \text { progression-free survival } \\ \text { PST } & \text { primary systemic therapy } \\ \text { ROC } & \text { Receiver Operating Characteristic } \\ \text { SD } & \text { standard deviation } \\ \text { TIL } & \text { tumor infiltrating lymphocytes }\end{array}$

\section{Background}

In breast carcinomas several predictive and prognostic markers have already been defined and used in the daily clinical routine, i.e. TNM stage, tumor grading and biological subtyping $[1,2]$. In locally advanced breast cancers, primary systemic therapy (PST) is the recommended first therapeutic approach $[1,3]$. However, there is still a need to find reliable and reproducible biomarkers, which can predict pathologic complete remission (pCR) and patients' prognosis, in order to select those who surely benefit from PST. The markers of cell proliferation are promising candidates for this clinical goal [4]. Ki-67 labeling index (Ki-67 LI) is routinely used to assess proliferation activity of breast tumors [1, 2]. However, it should be highlighted that contradictory data are presented about the reliability of $\mathrm{Ki}-67 \mathrm{LI}$ to assess tumor proliferation due to its relatively low inter-laboratory reproducibility $[5,6]$.

In case of breast carcinoma only a few studies are available which are investigating the predictive and prognostic role of cell cycle markers besides the Ki-67 LI [7-10]. The minichromosome maintenance protein complex (MCM2-7), Cyclin A, E and D1, geminins, Aurora kinase A and B and the phosphohistone-H3 (H3S10ph referred to as PHH3) are the most frequently investigated biomarkers in these studies [4, 7]. Our research group aimed to test the role of MCM2, Cyclin $\mathrm{A}$ and $\mathrm{PHH} 3$ as potential biomarkers predicting response to treatment and clinical outcome of locally advanced breast cancer.

Like $\mathrm{Ki}-67$, the MCM-complex is expressed during the whole cell cycle, except for G0 [11]. The MCM complex contains six replicative helicases (MCM2-7) which play a crucial role in replication initiation/licensing. Expression of these proteins cover a wider range of cycle than does $\mathrm{Ki}-67$ of which the function starts in G1-S, and stays active until the anaphase, connecting to the condensing chromosomes in G2 [11]. MCMs are already expressed in cells committed toward cell-division and are part of the pre-replication complex, as well $[12,13]$. Loddo et al. also highlighted the importance of S/G2 and M-phase markers besides MCM2, to form further cell-cycle activity-based subgroups of breast cancer with different prognostic potential [7]. For the former, Cyclin A is a good example, as being an S-phase checkpoint and DNArepair regulator, expressed from the $\mathrm{S}$-phase till its role in the G2/M-transition. Therefore it is a suitable marker of the
$\mathrm{S} / \mathrm{G} 2$ phases [7, 14]. As an independent M-phase marker, we used PHH3 in our current study. PHH3 is one of the proteins responsible for chromatin condensation; therefore $\mathrm{PHH} 3$ is an M-phase marker accurately reflecting the mitotic activity of the cell [15-17].

Pre-therapy Ki-67 LI (measured in core-biopsies before the initiation of PST) have already been proved to be predictive for $\mathrm{pCR}$ in breast cancer patients, but the best predictive cutoff point for the favorable outcome is under debate [18-20]. In our earlier published study [21] we proved that - besides the $\mathrm{Ki}-67 \mathrm{LI}$ - the higher expression of MCM2, Cyclin A and PHH3 also accurately anticipates pCR. For these cell-cycle markers we also defined predictive cut-off points to $\mathrm{pCR}$ for the clinical routine, to improve objectivity.

Besides its predictive value the prognostic potential of $\mathrm{Ki}$ 67 - namely that high expression of $\mathrm{Ki}-67$ is associated with a poor prognosis and with an earlier onset of metastatic disease - has also been confirmed, but different prognostic cut-off points were defined in the earlier published literature [18-20]. It was also higlighted by Fasching et al., that the predictive and the prognostic cut-off points must be defined separately for the Ki-67 LI. In their study they defined $40 \%$ positivity cut-off point for $\mathrm{pCR}$ alone and a $13 \%$ positivity cut-off point to be prognostic for both pCR and OS [22]. The 13 th St. Gallen consensus defined a $14 \%$ positivity cutoff point to differentiate prognostic groups of breast cancer based on the biological behaviour of the tumors, but later suggested a different, namely $20 \%$ cut-off to be used for response prediction [2]. In our earlier published study [23] we defined a $20 \%$ prognostic cut-off of $\mathrm{Ki}-67 \mathrm{LI}$ for progressionfree survival (PFS) and a $30 \%$ for overall survival (OS), respectively, but as a predictive cut-off, $45 \%$ was specified [21].

In addition to $\mathrm{Ki}-67, \mathrm{MCM} 2$ expression also seems to have prognostic value in breast cancer $[8,12]$. MCM2 positivity ratio of over $30 \%$ was found to be prognostic for poorer clinical outcome by Loddo et al. [7]. Cyclin A also has possible prognostic potential in breast cancers: higher Cyclin A expression (over $8.5 \%-10.5 \%$ ) is associated with worse prognosis [24-26]. PHH3 based mitotic-index proved to be a stronger prognostic factor than the regularly applied mitotic activity index measured on hematoxylin-eosin stained slides [15-17]. According to Skaland et al., if the rate of M-phase cells was over 13 mitosis/10 NNL it was associated with poor prognosis [17].

In our current study we aimed to further investigate the correlation between these nuclear protein markers either expressed throughout (Ki67, MCM2), from post G1 (Cyclin A) or in M-phase (PHH3) of the cell cycle and the routinely examined clinicopathological factors of breast cancers undergoing PST (i.e. histological type, tumor grade, cTNM stage, biological behavior and tumor subtypes). Additionally, a novel prognostic biomarker, the presence of tumor infiltrating lymphocytes (TIL) was also assessed in our study. Over its 
prognostic significance, the predictive value of TIL infiltration is under debate in the neoadjuvant setting and its association with tumor proliferation has not been investigated thoroughly yet [27]. Prognostic value of the investigated cell cycle markers were also assessed regarding PFS and OS. For histological analyses and immunohistochemistry we used corebiopsy samples taken before the initiation of the neoadjuvant treatment.

\section{Materials and Methods}

\section{Study Population}

Patients diagnosed with primary breast cancer and treated with PST at the Oncology Center of Semmelweis University were retrospectively identified. Inclusion and exclusion criteria were the same as applied in our earlier study published previously [21]. Briefly, inclusion criteria were the following: (1) diagnosis of breast cancer (between 2008 and 2014) confirmed by ultrasound guided core biopsy sampling; (2) first oncological treatment was PST, initiated between 1 January 2008 and 31 December 2013 (end of follow up: 31 May 2017); (3) lack of any distant metastasis at the time of breast cancer diagnosis confirmed by ${ }^{18} \mathrm{~F}$-fluorodeoxy-glucose positron emission tomography and computer tomography (FDG-PET/CT) examinations; (4) patients included in the final analysis were those who underwent surgery after completion of PST.

Clinical TNM was assessed by using routinely applied diagnostic imaging modalities (X-ray and ultrasound mammography, and FDG-PET/CT).

The study was ethically approved by the Semmelweis University Institutional Review Board (No.: SE TUKEB 120/2013).

\section{Histopathological Analysis and Pathological Response Evaluation}

Before PST detailed histological characterization was performed on the core biopsy samples (i.e. histological type, nuclear grade, tubule formation score, mitotic index, presence or absence of in situ carcinoma component, perineural and lymphovascular invasion). Additionally, the core-biopsy samples were evaluated for the presence of tumor infiltrating lymphocytes (TIL) in the stroma of the tumors according to the TILs Working Group guideline published in 2015 [27].

In surgical samples, if residual tumor was present, histological characterization was repeated; in addition, residual tumor size and nodal stage were also assessed with the evaluation of tumor-free margins. For pathological response evaluation the surgical samples were analyzed according to national consensus recommendations [28] based on the Pinder [29] response classification: the response of the primary tumors (TR1-3 categories) and regional lymph nodes (NR1-4 categories) were assessed separately. pCR was diagnosed only if no viable invasive tumor cells were identified in the breast specimen after the whole tumor bed and the resected axillary lymph nodes were embedded and thoroughly investigated. Presence of ductal carcinoma in situ (DCIS) was allowed, the pCR was defined as ypT0/Tis [30].

\section{Immunohistochemistry}

Formalin-fixed, paraffin-embedded pre-treatment core biopsy samples were examined. Immunohistochemistry (IHC) was routinely performed to evaluate hormone receptor - estrogen (ER) and progesterone (PR) - status, as well as HER2 expression according to international guidelines. Hormone receptor positivity was confirmed if Allred score was above or equal to 3 [31]. HER2 overexpression was defined as IHC 3+. HER2 $1+$ or 0 tumors were considered Her 2 negative. For IHC $2+$ samples, fluorescent in situ hybridization (FISH) was performed to confirm gene amplification. HER2 status was defined according to the ASCO/CAP Guideline valid at the time of diagnosis, i.e. HER2-positive patients treated between January 2008 and November 2013 were identified according to the 2007 ASCO/CAP Guideline [32] and from then on according to the Guideline published in October 2013 [33]. Using these parameters and the value of the Ki-67 LI, described below - biological subtype of the tumors was defined according to the recommendations of the 13th St. Gallen International Breast Cancer Conference [2].

Ki-67, MCM2, Cyclin A and PHH3 were stained as described previously by Tőkés et al. [21]. Proliferation markers were scored by two investigators (TT and AMT) as described earlier [34, 35]. Briefly, every slide was assessed visually and the proportion of positive cells was determined by counting approximately 500 tumor cells at 400x magnifications. For Ki-67, MCM2 and Cyclin A markers, a cell was considered positive if any nuclear signal was observed, similar to the studies of Ali et al. [36] and Tökés et al. [9]. Intensity was scored based on the recommendation of Dowsett et al. [34]. Regarding $\mathrm{PHH} 3$ - over quantifying the proportion of positive cells as described above - an additional evaluation of mitotic count was also performed in 10 high-powered fields (HPF) at 400x magnifications, as described earlier by Bossard et al. [15]. Briefly, only those nuclei were counted as $\mathrm{PHH} 3$ positive which were characterized by strong and dense staining of chromatin clumps, representing prophase, metaphase, anaphase and telophase. PHH3 nuclei with fine granular staining were excluded from the counting as representing interphase nuclei. 


\section{Statistical Analysis}

All applied statistical tests were two-sided and $p$ values $<0.05$ were considered significant. Data were expressed as mean \pm standard deviation (SD). Normality was tested by using Shapiro-Wilks test. Connections between clinicopathological characteristics and expressions of the investigated cell cycle proteins were assessed by using Mann-Whitney and Kruskal-Wallis tests. To compare pCR and non-pCR patient groups Mann-Whitney tests were performed.

PFS was evaluated after 2 years follow-up and at the end of the follow-up period (31 May 2017), together with OS. The data of those patients who did not experience progression or cancer-related death was censored at the last control visit at the Oncology Center of Semmelweis University. Patients who experienced progression and those who did not were compared by means of clinicopathological characteristics using Mann-Whitney and Kruskal-Wallis tests. Moreover logistic regression was performed to assess the prognostic potential of the tested cell-cycle markers to PFS. For survival analyses, Kaplan-Meier product limit methods were used with log-rank tests to compare patient groups defined by the high or low expression of proliferation markers. For Ki-67 we used cutoff points described earlier by our research group (for Ki-67 LI 20\% for PFS and 30\% for OS [23]); for the other markers we applied earlier published prognostic cut-off points as follows: for MCM2 30\% [7], for Cyclin A 10.5\% [26], for PHH3 13 mitosis/10 NNL [17].

Additionally, based on the hypothesis of Loddo et al. [7] we grouped our patients in four clusters concerning the expression of the investigated proliferation markers over the routinely used Ki-67 LI. For subgrouping we also used the above described prognostic cut-off points, as follows:

- Group I) low MCM2 expression with any Cyclin A, any PHH3 expression

- Group II) high MCM2 but low Cyclin A and low PHH3 expression

- Group III) high MCM2 with high Cyclin A and low PHH3 expression

- Group IV) high MCM2, high Cyclin A and high PHH3 expression

- Group V) other tumors (with high MCM 2, low Cyclin A and high $\mathrm{PHH} 3$ expression).

Subgroups were compared using heatmap analysis, regarding the distribution between biological subgroups and clinical outcome.

Microsoft Excel 2010 (Microsoft Corp., Redmond Washington, USA) and Statistica 13.2 (StatSoft Inc., Tulsa, Oklahoma, USA) software were used for data collection and processing.

\section{Results}

\section{Clinicopathological Characteristics and Expression of the Cell-Cycle Markers}

A total of 52 breast cancer patients (mean age: $48.02 \pm$ 10.51 years) were enrolled in our current study (Table 1). Dominantly grade $3(32 / 52,62 \%)$ invasive breast carcinomas of no special type (IBC NST) $(48 / 52,92 \%)$ were evaluated. 33 tumors were ER-positive, 30 PR-positive. HER2 positivity was identified in 21 cases. Seven tumors were luminal A-like and 27 were luminal B-like - from these 12 were luminal B-proliferative and 15 were luminal B-HER2 positive. 6 tumors were classified as HER2-positive subtype and 12 were triple negative.

Table 1 Clinicopathological characteristics of the tumors $(n=52)$

\begin{tabular}{|c|c|c|}
\hline Characteristics & No. & $\%$ \\
\hline \multicolumn{3}{|l|}{ Clinical T categories } \\
\hline $\mathrm{T} 1 \mathrm{c}$ & 5 & 9.6 \\
\hline $\mathrm{T} 2$ & 39 & 75 \\
\hline $\mathrm{T} 3$ & 5 & 9.6 \\
\hline $\mathrm{T} 4$ & 3 & 5.8 \\
\hline \multicolumn{3}{|l|}{ Clinical $\mathrm{N}$ categories } \\
\hline No & 21 & 40.4 \\
\hline N1 & 19 & 36.5 \\
\hline $\mathrm{N} 2$ & 5 & 9.6 \\
\hline N3 & 7 & 13.5 \\
\hline \multicolumn{3}{|l|}{ Histology } \\
\hline Invasive breast carcinomas of no special type (IBC NST) & 48 & 92.3 \\
\hline Other & 4 & 7.7 \\
\hline \multicolumn{3}{|l|}{ Grade } \\
\hline 1 & 0 & 0 \\
\hline 2 & 20 & 38.5 \\
\hline 3 & 32 & 61.5 \\
\hline \multicolumn{3}{|l|}{ Biological subtype } \\
\hline Luminal A & 7 & 13.5 \\
\hline Luminal B/proliferative & 12 & 23.1 \\
\hline Luminal B/Her2-positive & 15 & 28.8 \\
\hline Her2-positive & 6 & 11.5 \\
\hline Triple negative & 12 & 23.1 \\
\hline \multicolumn{3}{|l|}{ Primary systemic therapy } \\
\hline Taxane-anthracycline combination & 19 & 36.5 \\
\hline Taxane-platinum combination & 15 & 28.8 \\
\hline Trastuzumab-based combination & 11 & 21.2 \\
\hline Other & 7 & 13.5 \\
\hline \multicolumn{3}{|l|}{ Surgical therapy } \\
\hline Mastectomy & 35 & 67.3 \\
\hline Breast conserving surgery & 17 & 32.7 \\
\hline Axillary block dissection & 43 & 82.7 \\
\hline Sentinel lymph node biopsy & 9 & 17.3 \\
\hline
\end{tabular}


By analyzing the relationship between the expression of the investigated cell-cycle proteins and the known predictive and prognostic factors (i.e. cT and $\mathrm{cN}$ categories; histological type; nuclear grade; ER, PR and HER2 status; biological subtype) in pre-therapy core-biopsies (Table 2 ) we found significantly different expression of MCM2 and $\mathrm{PHH} 3$ according to $\mathrm{cT}$ categories: smaller lesions showed more pronounced tumor proliferation. Initial clinical N stage did not show any correlation with proliferation activity. Every cell cycle marker was significantly higher in grade 3 tumors compared to grade 2 lesions. Regarding hormone receptor status, we found that all markers but PHH3 showed higher expression in ER and PR negative tumors than in hormone receptor positive cancers. HER2 status did not show any correlation with tumor proliferation. Triple negative carcinomas showed higher proliferation activity than any other subtypes with every investigated marker.

We also analyzed the correlations between the presence of stromal TILs and the cell cycle activity of the primary tumors. Tumors with increased TIL score showed significantly higher Ki-67 expression $(p=0.04)$. The other three cell-cycle markers were also higher in tumors with high TIL score than those with lower scores, but this tendency was not significant (Table 2). Core-biopsy TIL was significantly higher in those patients who achieved pCR compared to those with residual tumors ( $13.52 \%$ vs. $2.46 \%$, respectively; $p=0.0008)$.

\section{Pathological Response Rates and Cell Cycle Marker Expression}

All patients were treated with PST, most commonly in 3-week schedules, for 6 or 8 cycles. Mostly taxane-based regimens were administered $(n=48)$. After completion of PST, every included patient gave consent to surgery. Regarding the final histological analyses, 17 patients achieved pCR (17/52; $32.7 \%)$. We detected residual tumors in 35 cases $(35 / 52$, $67.3 \%$ ), from these in 4 cases (7\%) only the regional lymph nodes contained malignant cells. In 33 patients we did not detect any lymph node metastasis after the PST $(y p N 0=33 /$ 52; 63.5\%), in 19 patients nodal involvement was confirmed, but from these in one case only a micrometastasis was detected. Among residual tumors, dominant subtypes were the luminal ones: 22/35 (63\%) tumors were luminal B-like - from these 11 were luminal B-proliferative and 11 were luminal BHER2 positive - and 7/35 (20\%) lesions were luminal A-like.

We found significantly higher initial Ki-67, MCM2, Cyclin $\mathrm{A}$ and $\mathrm{PHH} 3$ expression in the $\mathrm{pCR}$ cases compared to nonpCR patients $(p<0.0001, p=0.0024, p=0.0032$ and $p=$ 0.0294 , respectively). Additionally, strong significance was found when the initial cell cycle activity (Ki-67, MCM2, Cyclin A and PHH3 expression) of ypT0/is patients was compared with other ypT stages. However, we did not find any significant correlation between the initial cell-cycle activity and the lymph node involvement (ypN0 vs. other ypN stages) after the PST (Table 3).

We also assessed residual tumors according to the degree of tumor response. We assessed the residual primary tumors and regional lymph nodes separately. From the 31 cases with residual primary tumors we detected a therapeutic response to PST in 23 patients $(23 / 31,74 \%)$ and only 8 patients showed no evidence of tumor response (TR3: 8/31, 26\%). The partial responder tumors were distributed between TR2a, TR2b and TR2 $c$ response categories unevenly $(5,7$ and 11 patients, respectively). We did not find significant correlation between the degree of tumor response detected in the primary lesions after surgery and the initial cell-cycle activity in the core-biopsies. Amongst the cases with node positive disease detected after PST, only nine patients showed signs of therapeutic response $(9 / 19,47 \%)$ while in ten patients $(10 / 19,53 \%)$ the nodal metastases showed no evidence of response to therapy. Regarding regional lymph nodes, we did not find any correlation between the NR response status and the initial cell-cycle activity, similarly to the primary lesions. (Detailed results are presented in Table 3).

\section{Survival Analysis}

Median follow-up time was 62 months. We detected disease progression in 12 cases $(12 / 52 ; 23 \%)$. From these, 8 patients belonged to the non-pCR patient group after PST. However, we did not find any significant differences between these 12 patients and the rest of the patients $(40 / 52)$ regarding the initial expression of Ki-67 ( $p=0.277)$, MCM2 $(p=0.583)$, Cyclin A $(p=0.724)$ or PHH3 $(p=0.267)$ measured in the core-biopsy samples. Additionally, from the 12 cases with progression 7 $(7 / 12 ; 58 \%)$ were considered as early onset relapse (PFS $\leq 2$ years). From these seven cases in 6 patients the expression of every tested cell cycle markers was high in the core-biopsy samples, but we could not prove any significant predictive potential of the initial Ki-67 $(p=0.097)$, MCM2 $(p=0.172)$, Cyclin A $(p=0.932)$ or PHH3 $(p=0.380)$ expression towards early relapse.

Five patient deceased during the follow-up (9.6\%), all death were cancer-related and all of these patients experienced non-pCR after the PST. In four of these five patients (80\%), every cell cycle marker was elevated in their pre-treatment core-biopsy samples.

Based on Kaplan-Meier analysis and log rank tests we could not prove any significant prognostic potential of the tested cell cycle markers towards PFS or OS (see Additional file 1).

\section{Pattern Analysis}

We performed further subgrouping of the patients based on the expression pattern of the investigated - relatively phase 
Table 2 Relationship between the clinicopathological characteristics and the expression of cell-cycle markers in core biopsy specimens

\begin{tabular}{|c|c|c|c|c|}
\hline Feature (No. of tumors) & Ki-67 mean & MCM2 mean & Cyclin A mean & PHH3 mean \\
\hline \multicolumn{5}{|l|}{ Clinical T categories } \\
\hline $\mathrm{T} 1(5)$ & 70.00 & 70.00 & 43.00 & 16.00 \\
\hline T2 (39) & 48.52 & 55.38 & 24.59 & 8.38 \\
\hline $\mathrm{T} 3(5)$ & 46.00 & 50.00 & 20.00 & 6.00 \\
\hline $\mathrm{T} 4$ (12) & 31.66 & 16.67 & 16.67 & 8.34 \\
\hline $\mathrm{p}$ value & 0.2157 & $\underline{0.0225}$ & 0.0830 & $\underline{0.0468}$ \\
\hline \multicolumn{5}{|l|}{ Clinical $\mathrm{N}$ categories } \\
\hline N0 (21) & 42.86 & 49.29 & 21.52 & 8.43 \\
\hline N1-3 (31) & 53.77 & 57.26 & 28.13 & 9.19 \\
\hline $\mathrm{p}$ value & 0.1366 & 0.2578 & 0.2135 & 0.3739 \\
\hline \multicolumn{5}{|l|}{ Histology * } \\
\hline IDC (48) & 50.98 & 55.00 & 26.39 & 9.17 \\
\hline other (4) & 30.00 & 42.50 & 14.25 & 5.50 \\
\hline \multicolumn{5}{|l|}{ Nuclear grade } \\
\hline II $(20)$ & 32.60 & 38.35 & 17.20 & 6.85 \\
\hline III (32) & 59.84 & 63.91 & 30.63 & 10.63 \\
\hline$p$ value & $\leq 0.0001$ & $\leq 0.0001$ & $\underline{0.0003}$ & $\underline{0.0424}$ \\
\hline \multicolumn{5}{|l|}{ ER status } \\
\hline positive (33) & 37.33 & 45.61 & 19.97 & 7.64 \\
\hline negative (19) & 70.26 & 68.68 & 35.00 & 11.05 \\
\hline $\mathrm{p}$ value & $\leq 0.0001$ & $\underline{0.0003}$ & $\underline{0.0011}$ & 0.0544 \\
\hline \multicolumn{5}{|l|}{ PR status } \\
\hline positive (30) & 36.90 & 46.83 & 19.47 & 7.83 \\
\hline negative (22) & 66.36 & 66.86 & 33.64 & 10.32 \\
\hline $\mathrm{p}$ value & $\leq 0.0001$ & $\underline{0.0089}$ & $\underline{0.0013}$ & 0.1691 \\
\hline \multicolumn{5}{|l|}{ Her2 status } \\
\hline positive (21) & 47.86 & 50.00 & 24.52 & 8.67 \\
\hline negative (31) & 50.39 & 56.77 & 26.09 & 9.03 \\
\hline $\mathrm{p}$ value & 0.8245 & 0.2500 & 0.9558 & 0.7958 \\
\hline \multicolumn{5}{|l|}{ Triple negativity } \\
\hline no $(40)$ & 41.30 & 47.63 & 12.72 & 7.55 \\
\hline yes (12) & 76.25 & 75.42 & 37.92 & 13.34 \\
\hline $\mathrm{p}$ value & $\leq 0.0001$ & $\leq 0.0001$ & $\underline{0.0046}$ & $\underline{0.0053}$ \\
\hline \multicolumn{5}{|l|}{ Biological subtype } \\
\hline Luminal A (7) & 19.57 & 37.14 & 8.43 & 4.71 \\
\hline Lum.B-prolif. (12) & 42.50 & 49.58 & 24.58 & 7.25 \\
\hline Lum.B-Her2 + (15) & 41.66 & 48.00 & 21.00 & 9.13 \\
\hline Her2-positive (6) & 63.33 & 55.00 & 33.33 & 7.50 \\
\hline Triple negative(12) & 76.25 & 75.42 & 37.92 & 13.34 \\
\hline $\mathrm{p}$ value & $\leq 0.0001$ & $\underline{0.0026}$ & $\underline{0.0004}$ & $\underline{0.0119}$ \\
\hline \multicolumn{5}{|c|}{ Tumor infiltrating lymphocytes (TIL) } \\
\hline $\mathrm{TIL} \leq 1 \%$ & 38.33 & 46.67 & 21.61 & 7.61 \\
\hline TIL $1-20 \%$ (19) & 57.37 & 53.95 & 28.42 & 10.37 \\
\hline TIL > 20\% (6) & 60.00 & 58.33 & 34.17 & 7.17 \\
\hline $\mathrm{p}$ value & 0.0402 & 0.9676 & 0.4744 & 0.9970 \\
\hline
\end{tabular}

Underlined: statistically significant difference

*due to low case numbers and statistical power we did not perform a statistical comparison

\# missing in 9 patients 
Table 3 Relationship between the rate of tumor response and the expression of cell cycle markers in core biopsy specimens

\begin{tabular}{|c|c|c|c|c|}
\hline Feature (No. of tumors) & $\begin{array}{l}\text { Ki-67 } \\
\text { mean }\end{array}$ & $\begin{array}{l}\text { MCM2 } \\
\text { mean }\end{array}$ & $\begin{array}{l}\text { Cyclin A } \\
\text { mean }\end{array}$ & $\begin{array}{l}\mathrm{PHH} 3 \\
\text { mean }\end{array}$ \\
\hline $\mathrm{pCR}(n=17)$ & 68.53 & 67.65 & 35.00 & 11.06 \\
\hline non-pCR $(n=35)$ & 40.06 & 47.43 & 20.83 & 7.830 \\
\hline$p$ value ( $p C R$ vs non- $p C R$ ) & $\leq 0.0001$ & $\underline{0.0024}$ & $\underline{0.0032}$ & $\underline{0.0294}$ \\
\hline \multicolumn{5}{|l|}{ ypT categories ${ }^{1}$} \\
\hline ypT0/is $(n=21)$ & 65.95 & 67.38 & 34.52 & 10.86 \\
\hline $\operatorname{ypT} 1(n=11)$ & 47.27 & 49.09 & 23.64 & 9.73 \\
\hline $\operatorname{ypT} 2(n=13)$ & 34.00 & 47.31 & 18.23 & 5.38 \\
\hline ypT3 $(n=4)$ & 31.25 & 37.50 & 9.25 & 5.50 \\
\hline ypT4 (n=2) & 35.00 & 25.00 & 20.00 & 7.50 \\
\hline $\mathrm{p}$ value (all compared) & $\underline{0.0031}$ & $\underline{0.0094}$ & $\underline{0.0017}$ & $\underline{0.0169}$ \\
\hline $\mathrm{p}$ value $(\mathrm{T} 0 / \text { is vs } \mathrm{T}+)^{*}$ & $\underline{0.0001}$ & $\underline{0.0005}$ & $\underline{0.0003}$ & $\underline{0.0056}$ \\
\hline \multicolumn{5}{|c|}{ Tumor response of the primary breast lesions } \\
\hline TR1a and $1 \mathrm{~b}(n=21)$ & 65.95 & 67.38 & 34.52 & 10.86 \\
\hline TR2a $(\mathrm{n}=5)$ & 31.00 & 58.00 & 22.00 & 12.00 \\
\hline $\operatorname{TR} 2 \mathrm{~b}(n=7)$ & 46.43 & 43.57 & 22.86 & 7.43 \\
\hline TR2c $(n=11)$ & 43.64 & 43.18 & 18.82 & 6.91 \\
\hline TR3 $(n=8)$ & 27.75 & 40.63 & 15.25 & 5.75 \\
\hline $\mathrm{p}$ value (all compared) & $\underline{0.0015}$ & $\underline{0.0091}$ & $\underline{0.0065}$ & $\underline{0.0291}$ \\
\hline $\mathrm{p}$ value (TR2a-3 compared) & 0.3500 & 0.5739 & 0.5411 & 0.3128 \\
\hline \multicolumn{5}{|l|}{ ypN categories ${ }^{2}$} \\
\hline ypN0 $(n=33)$ & 54.24 & 58.64 & 28.24 & 9.55 \\
\hline ypN1 $(n=10)$ & 40.7 & 50.50 & 18.70 & 7.70 \\
\hline ypN2 $(n=6)$ & 40.83 & 35.00 & 21.67 & 8.33 \\
\hline ypN3 (n = 2) & 32.50 & 55.00 & 22.50 & 5.00 \\
\hline $\mathrm{p}$ value (all compared) & 0.3275 & 0.1753 & 0.3149 & 0.7039 \\
\hline $\mathrm{p}$ value (N0 vs $\mathrm{N}+$ )\# & 0.0743 & 0.0810 & 0.0846 & 0.5912 \\
\hline \multicolumn{5}{|c|}{ Remission rate in the axillary lymph nodes } \\
\hline NR1 (n=33) & 54.24 & 58.64 & 28.24 & 9.55 \\
\hline NR3 $(n=9)$ & 47.78 & 45.56 & 23.00 & 8.00 \\
\hline NR4 $(n=10)$ & 34.7 & 46.5 & 18.50 & 7.50 \\
\hline $\mathrm{p}$ value (all compared) & 0.1162 & 0.1929 & 0.1990 & 0.8292 \\
\hline p value (NR3 vs NR4) & 0.1564 & 0.8421 & 0.4469 & 0.6607 \\
\hline
\end{tabular}

Underlined: statistically significant difference

[1] one specimen with a micrometastasis was excluded from these analyses

[2] one specimen with a micrometastasis was excluded from these analyses

*ypT0/is patient group compared to patients with pathological stages ypT1a or greater

\# ypN0 patient group compared to patients with pathological stages ypN1a or greater specific - cell-cycle proteins. The subgroups and distribution of the patients amongst the subgroups were as follows:

- Group I) low MCM2 expression with any Cyclin A, any PHH3 expression: $n=9$

- Group II) high MCM2 but low Cyclin A and low PHH3 expression: $n=2$

- Group III) high MCM2 with high Cyclin A and low PHH3 expression: $\mathrm{n}=2$
- Group IV) high MCM2, high Cyclin A and high PHH3 expression: $n=34$

- Group V) other tumors (with high MCM 2 with low Cyclin A and high PHH3 expression): $n=5$

A heatmap was designed to compare the four patient groups regarding biological tumor subtypes and clinical outcome (Fig. 1). Hormone receptor positive tumors with favorable outcome were more frequent in Group I and II. In comparison, only Group IV contained triple negative tumors and 


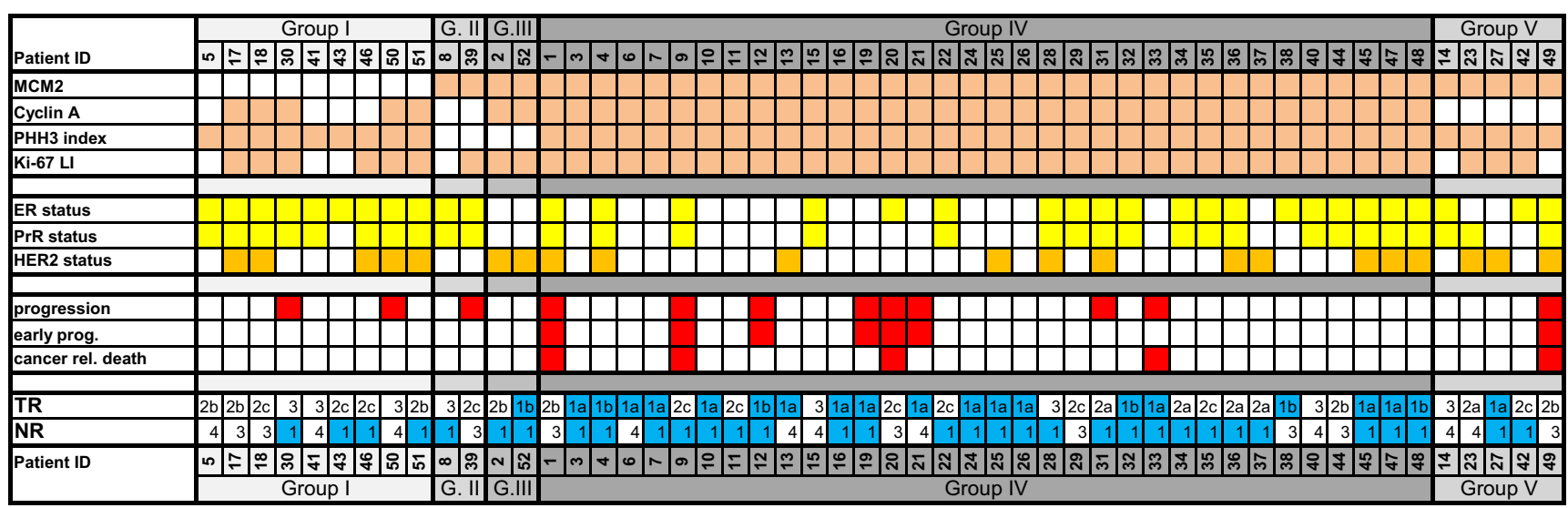

Fig. 1 Heat map. In the first block the peach colored cells represent those tumors showing high MCM2, Cyclin A, PHH3 and Ki-67 expression. In the second part yellow squares represent the ER, PR positive tumors and orange ones mark the HER2 positive lesions. In the third part red squares

this patient group showed the most favorable response to PST - almost all pCR cases grouped together into this most actively proliferating patient subgroup.

Nonetheless, regarding the rate of progression the most unfavorable results were also experienced in Group IV; from 34 patients 9 showed progression (26\%), whilst in the other three patient groups (Group I, II, III and V) only two, one, zero and one patient showed a relapse, respectively.

Kaplan-Meier plots comparing the PSF and OS of the patients in Group IV with the others are shown on Fig. 2. We did not find any significant differences between the survival of these two patient groups ( $p=0.907$ and $p=0.551$, respectively).

\section{Discussion}

Relationship between the clinicopathological characteristics of breast tumors and the routinely used Ki-67 proliferation

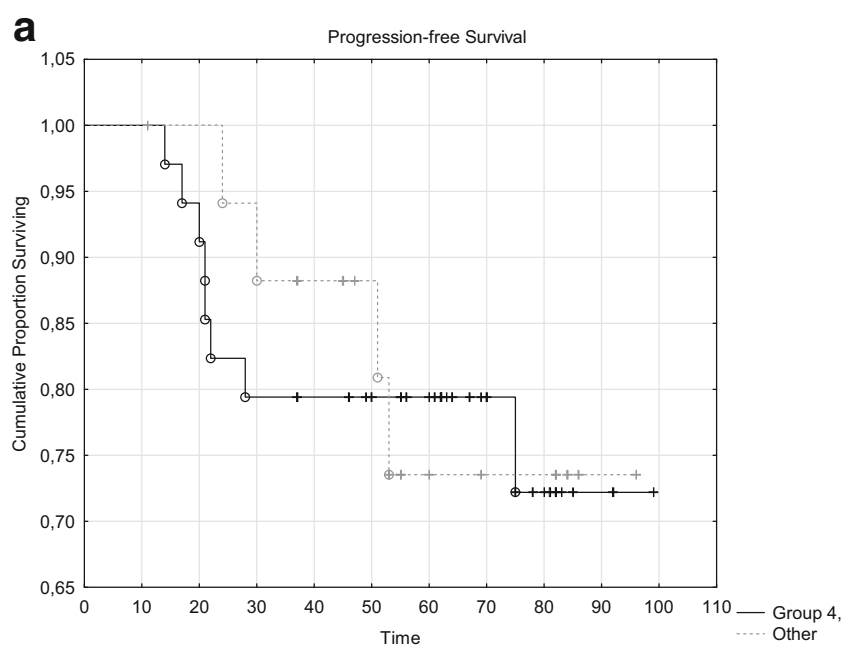

Fig. 2 Comparison of the PFS (a) and OS (b) of patients in Group IV (containing patients with high MCM2, high Cyclin A and high PHH3 expression) vs. the other investigated patient groups (Group I, II, III and V)

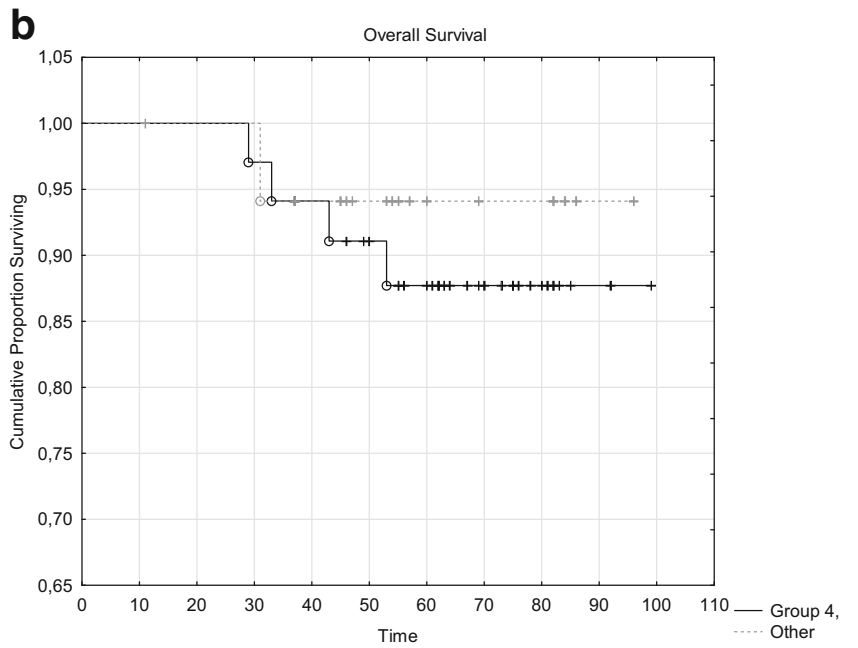

represent progressed cases. In the last part tumor response is detailed - in the primaries (TR) and in the lymph node region (NR) according to the Pinder classification

marker has already been established. However, due to the known analytical limitations of Ki-67 LI [5, 6], several other proliferation markers were already tested, but only a few studies analyzed the relationship of these cell-cycle markers and the known predictive and prognostic factors of locally advanced breast cancer.

In our study, while analyzing core-biopsy samples of locally advanced breast cancers, we found that smaller lesions (cT1 and cT2 tumors) showed higher proliferation activity measured by all investigated markers than larger tumors. In case of MCM2 and PHH3 these correlations were significant. If the axillary lymph node status was $>\mathrm{cN} 0$, as per clinical-imaging investigations, the expression of every proliferation marker was higher compared to clinically node-negative (cN0) cases, but the relationship was not significant. Earlier published results are contradictory regarding the investigated markers of our study. Wiesner et al. analyzed the data of more than one thousand patients and found significant correlation between 
the expression of $\mathrm{Ki}-67$ and tumor size as well as axillary involvement [37]. Other studies only described a relationship with tumor size but not with $\mathrm{cN}$ categories [38]. Correlation between the expression of MCM2 and tumor size was already described [39], like in case of PHH3 [17], but their connection with axillary involvement was not proved. Regarding Cyclin A neither tumor size nor axillary involvement was proved to be connected with the protein expression in one of the published studies [26], but two other studies proved a positive connection with the $\mathrm{cT}$ categories $[25,40]$.

The expression of all examined cell-cycle markers was higher in high-grade tumors, in agreement with earlier results $[17,26,37,39,41]$. It has to be highlighted that in case of grade 2 cancers with uncertain biological aggressiveness Ki$67 \mathrm{LI}$ can be used for further subgrouping into different prognostic groups [37]. Other markers applied in our study can also be applicable for this clinical purpose, therefore the selection of suitable patients for PST could be more accurate.

In case of hormone receptor negative (ER and PR negative) tumors every proliferation marker showed significantly higher expression - except PHH3 - compared to hormone receptor positive carcinomas. This correlation has already been described in case of Ki-67 [5, 37, 38], MCM2 [39], Cyclin A $[25,26,40]$ and even of PHH3 [17, 39].

In our study we did not find a significant correlation between HER 2 positivity and the expression of the investigated markers. Earlier studies also resulted in contradictory findings regarding the relationship between Ki-67 LI and HER2 expression. In some studies a positive correlation was described between these markers, while others did not find any correlation [36, 37]. Regarding MCM2 and Cyclin A similar contradictory results were published [25, 26, 36, 39]. PHH3 expression did not show any correlation with HER2 positivity [36], but it has been desribed that $\mathrm{PHH} 3$ expression positively correlates with nuclear atypia and negatively with tubule forming ability [17, 39].

Regarding biological subtypes defined in the core-biopsy samples we detected significantly higher expressions of all four cell-cycle markers in triple negative tumors, while in case of luminal A-like subtypes we found the lowest proliferation activity measured by every tested markers. We did not find any earlier published study on MEDLINE directly investigating the correlations between biological subtypes and MCM2, Cyclin A or PHH3 expression. Regarding the expression of Ki-67 LI it is already descibed that luminal A-like tumors (with the most favourable prognosis) have usually got low Ki-67 LI by definition. [2, 42] Notably, in these tumors pCR is rare when PST is applied [2, 43]. High Ki-67 LI can also be applied to define a patient subgroup amongst high grade, triple negative invasive breast carcinomas with high $\mathrm{pCR}$ rate but worse prognosis [44, 45]. The high expression of Ki-67, MCM2, Cyclin A and PHH3 is also in correlation with high grade and triple negativity, therefore all tested marker seem to be potentially applicable to delineate a patient group with biologically aggressive breast tumors to be suitable to PST.

TIL ratio of breast malignancies has been frequently investigated lately due to its possible connection to the efficiency of immunotherapies and its strong prognostic potential for favourable clinical outcome - but this prognostic potential depends on the biological subtypes of the tumors. Lymphocyte predominant tumors have favorable clinical response to chemotherapy amongst triple negative cancers and to trastuzumab in HER2 positive cases, but not in hormone receptor positive breast malignancies [27, 46]. In our study we found significantly higher infiltration of TIL in the core biopsies of tumors that achieved pCR. When assessing the relationship between the presence of TIL in the primaries and proliferation activity of these tumors, we did not find any earlier published study on MEDLINE directly investigating the correlations between TIL ratio and MCM2, Cyclin A or PHH3 expression. Regarding Ki67 , it has been recently proved that the presence of immune cells are related to the high proliferation activity of breast tumors - together with high grade and hormone receptor negativity [47]. Our study confirmed this correlation, but did not find any significant relationship between the presence of TIL and the expression of MCM2, Cyclin A or PHH3.

Regarding the predictive and prognostic potential of the investigated markers our study partially supported, but partially disproved earlier published results. As mentioned earlier initial $\mathrm{Ki}-67 \mathrm{LI}$ have already been proved to be predictive for pCR in breast cancer patients [18-20]. In our study pCR rate was relatively high $(17 / 52,32.7 \%)$ in the surgical specimens compared to international results [1-3]. HER2 positive and triple negative tumors were predominant in the pCR patient group and amongst non-pCR patients the majority had breast cancer with luminal characteristics- in accordance with the international literature [1-3]. In our current as well as in our earlier published results [21] we proved that besides $\mathrm{Ki}$ 67, the higher expression of MCM2, Cyclin A and PHH3 also accurately predicts the pCR after PST.

However, we did not find any significant correlation between the degree of the tumor response in the non-pCR patients (neither in the primary tumors nor the involved axillary lymph nodes) and the initial cell-cycle activity of the tumors. Besides the strong predictive potential of high cellproliferation activity towards $\mathrm{pCR}$, we revealed a lack of any reliable biomaker to differentiate between tumors with partial tumor remission. In the international literature we did not find any earlier published study directly investigating the correlations between TR and NR response grading and MCM2, Cyclin A or PHH3 expression. Regarding the Ki-67 LI, in the earlier study of our research group we could not find any correlation between $\mathrm{Ki}-67 \mathrm{LI}$ and rate of tumor response. However, the difference was significant when the $\mathrm{pCR}$ group and partial pathological responder group were compared, with the exclusion of those tumors which did not show any 
reactions to the applied neoadjuvant regimens, in agreement with the results of Balmativola et al. [20, 23].

Concerning prognostic potential it is well-known that high expression of $\mathrm{Ki}-67$ is associated with poor prognosis and earlier onset of metastatic progression $[18,19]$. However, contradictory data are presented about the reliability of Ki-67 LI to assess tumor proliferation: Ki-67 LI has a relatively low interlaboratory reproducibility and there is an active debate about the predictive and prognostic cut-off values advised for the daily routine $[5,6]$. Based on our study it can be stated that progression was more frequent amongst the tumors with higher proliferation activity, but the association was not significant.

Nonetheless, Loddo et al. [7] already suggested a novel approach in the assessment of core-biopsy samples using proliferation activity to differentiate between patient groups with different therapeutic sensitivity and prognosis. They assessed different, relatively phase-specific markers of the cell-cycle paralelly and form subgroups of the patients based on the relative ratio of tumor cells overexpressing $\mathrm{G} 1 / \mathrm{S} / \mathrm{G} 2$ and $\mathrm{M}$ phase markers. Based on their hypothesis we formed five patient groups concerning the expression of MCM2, Cyclin A and PHH3. Our results suggested that cell cycle marker-based subgrouping performed on core-biopsy samples could be used to accurately differentiate between tumors with different response to PST and prognosis. Additionally, we have to highlight that in our study we mostly investigated tumors fit to the 'phenotype III/actively cycling' tumor group of the Loddo study [7] (this group corresponds to Group III, IV an d V of our study) - being in harmony to the desirable goal that every patient of our study was selected to be an ideal candidate of PST. Only two patients could be classified to 'phenotye II/G1-delayed/arrested' tumors of the Loddo study [7] (this group corresponds to Group II of our study) in whom classic S and M cell-cycle-phase-targeted agents - like the widely used taxane and anthracyclin chemotherapies - may not be as effective than in actively cycling cells (amongst these patients pCR was not observed in our study and the response to the applied therapy was minimal). These tumors are more likely to benefit from G1-phase targeted agents or non-cell-cycle-specific anticancer drugs [7].

The limitation of our study is the few disease related events during the follow-up period of our patients, therefore the statistical power of the performed survival analyses is weak. Additionally, to further investigate the clinical usefulness of the above described cell-cycle based subgrouping further studies are needed with higher number of included patients.

\section{Conclusions}

Selecting patients diagnosed with breast cancer for PST is a critical problem in the daily practice. In our current study the pCR rate was relatively high, compared to international data; however, further assessment of the pretreatment core-biopsies is still advised to define supplementary biomarkers to increase the efficiency of the patient selection.

In our current study, we evaluated nuclear protein markers either expressed throughout (Ki67, MCM2), from post G1 (Cyclin A) or in M-phase (PHH3) of the cell cycle and their connections with the routinely used predictive and prognostic factors in breast cancer. Significant associations were described between the cell-cycle activity and the cT stage, grade, hormone receptor status and triple negativity of the investigated tumors. Novel biomarkers of tumor response and survival such as the presence of TILs - which was associated with more frequent occurrence of pCR - are also related to cell-proliferation, however, only Ki-67 showed significant correlation with stromal TIL.

We already proved that $\mathrm{Ki}-67, \mathrm{MCM} 2$, Cyclin A and PHH3 are good predictors of pCR after the PST, however, not only $\mathrm{pCR}$, but also rate of partial tumor remission is prognostic for the clinical outcome. In our current study, we did not find significant correlation between the degree of tumor response and the initial cell-cycle activity.

Regarding prognostic significance, the pattern of cell-cycle protein expression could be promising as predictive and prognostic tool to be applied before the initiation of PST as well as be useful to choose the therapeutic agent applied in this setting.

Acknowledgements The entire research group would like to express their gratitude for the assistance of Enikö Grineusz in the collection of the selected paraffin-embedded tissue samples from the Institutional Collection and we also thank Erzsébet Kovács for her invaluable technical help in cutting the sections.

Funding Information Open access funding provided by Semmelweis University (SE). Funding was provided by the Doctoral School of the Semmelweis University, in the form of student scholarship and $\mathrm{PhD}$ budget, granted to Tímea Tökés. The study was co-financed from a 1-year student scholarship by the Hungarian Cancer Society awarded to Tímea Tökés and the New National Excellence Program (ÚNKP-17-4-III-SE71) and STIA 19/2017, 6800313113, 68003F0043 scholarships awarded to Anna-Mária Tökés.

Data Availability The datasets generated during and/or analysed during the current study are available from the corresponding author on reasonable request.

\section{Compliance with Ethical Standards}

Conflict of Interest The authors declare that they have no conflict of interest.

Ethical Approval All procedures performed in studies involving human participants were in accordance with the ethical standards of the institutional and/or national research committee and with the 1964 Helsinki declaration and its later amendments or comparable ethical standards.

Ethical approval for the study was given by the Semmelweis University Institutional Review Board (SE-TUKEB), the number of the ethical approval is SE-TUKEB 120/2013 (Date of approval: 12 June 2013). Written informed consent was waived 
Open Access This article is distributed under the terms of the Creative Commons Attribution 4.0 International License (http:// creativecommons.org/licenses/by/4.0/), which permits unrestricted use, distribution, and reproduction in any medium, provided you give appropriate credit to the original author(s) and the source, provide a link to the Creative Commons license, and indicate if changes were made.

\section{References}

1. Goldhirsch A, Wood WC, Gelber RD, Coates AS, Thurlimann B, Senn HJ, Gallen S (2007) Progress and promise: highlights of the international expert consensus on the primary therapy of early breast cancer. Ann Oncol 18:1133-1144

2. Goldhirsch A, Winer EP, Coates AS, Gelber RD, Piccart-Gebhart M, Thurlimann B et al (2013) Personalizing the treatment of women with early breast cancer: highlights of the St Gallen international expert consensus on the primary therapy of early breast cancer. Ann Oncol 24:2206-2223

3. Kaufmann M, von Minckwitz G, Bear HD, Buzdar A, McGale P, Bonnefoi $\mathrm{H}$ et al (2007) Recommendations from an international expert panel on the use of neoadjuvant (primary) systemic treatment of operable breast cancer: new perspectives. Ann Oncol 18:1927-1934

4. Colozza M, Azambuja E, Cardoso F, Sotiriou C, Larsimont D, Piccart MJ (2005) Proliferative markers as prognostic and predictive tools in early breast cancer: where are we now? Ann Oncol 16:1723-1739

5. Bottini A, Berruti A, Bersiga A, Brizzi MP, Bruzzi P, Aguggini S et al (2001) Relationship between tumour shrinkage and reduction in Ki67 expression after primary chemotherapy in human breast cancer. Br J Cancer 85:1106-1112

6. Polley MY, Leung SC, McShane LM, Gao D, Hugh JC, Mastropasqua MG et al (2013) International Ki67 in Breast Cancer Working Group of the Breast International G, North American Breast Cancer G. An international Ki67 reproducibility study. J Natl Cancer Inst 105:1897-1906

7. Loddo M, Kingsbury SR, Rashid M, Proctor I, Holt C, Young J et al (2009) Cell-cycle-phase progression analysis identifies unique phenotypes of major prognostic and predictive significance in breast cancer. Br J Cancer 100:959-970

8. Shetty A, Loddo M, Fanshawe T, Prevost AT, Sainsbury R, Williams GH et al (2005) DNA replication licensing and cell cycle kinetics of normal and neoplastic breast. Br J Cancer 93:1295-1300

9. Tokes AM, Szasz AM, Geszti F, Lukacs LV, Kenessey I, Turanyi E et al (2015) Expression of proliferation markers Ki67, cyclin A, geminin and aurora-kinase $\mathrm{A}$ in primary breast carcinomas and corresponding distant metastases. J Clin Pathol 68:274-282

10. Whitfield ML, George LK, Grant GD, Perou CM (2006) Common markers of proliferation. Nat Rev Cancer 6:99-106

11. Endl E, Gerdes J (2000) The Ki-67 protein: fascinating forms and an unknown function. Exp Cell Res 257:231-237

12. Williams GH, Stoeber K (2012) The cell cycle and cancer. J Pathol 226:352-364

13. Lei M (2005) The MCM complex: its role in DNA replication and implications for cancer therapy. Curr Cancer Drug Targets 5:365-380

14. Vermeulen K, Van Bockstaele DR, Berneman ZN (2003) The cell cycle: a review of regulation, deregulation and therapeutic targets in cancer. Cell Prolif 36:131-149

15. Bossard C, Jarry A, Colombeix C, Bach-Ngohou K, Moreau A, Loussouarn D et al (2006) Phosphohistone H3 labelling for histoprognostic grading of breast adenocarcinomas and computerassisted determination of mitotic index. J Clin Pathol 59:706-710

16. Skaland I, Janssen EA, Gudlaugsson E, Hui Ru Guo L, Baak JP (2009) The prognostic value of the proliferation marker phosphohistone $\mathrm{H} 3$ (PPH3) in luminal, basal-like and triple negative phenotype invasive lymph node-negative breast cancer. Cell Oncol 31:261-271

17. Skaland I, Janssen EA, Gudlaugsson E, Klos J, Kjellevold KH, Soiland H, Baak JP (2009) Validating the prognostic value of proliferation measured by Phosphohistone H3 (PPH3) in invasive lymph node-negative breast cancer patients less than 71 years of age. Breast Cancer Res Treat 114:39-45

18. de Azambuja E, Cardoso F, de Castro G Jr, Colozza M, Mano MS, Durbecq V et al (2007) Ki-67 as prognostic marker in early breast cancer: a meta-analysis of published studies involving 12,155 patients. Br J Cancer 96:1504-1513

19. Inwald EC, Klinkhammer-Schalke M, Hofstadter F, Zeman F, Koller M, Gerstenhauer M et al (2013) Ki-67 is a prognostic parameter in breast cancer patients: results of a large population-based cohort of a cancer registry. Breast Cancer Res Treat 139:539-552

20. Balmativola D, Marchio C, Maule M, Chiusa L, Annaratone L, Maletta F et al (2014) Pathological non-response to chemotherapy in a neoadjuvant setting of breast cancer: an inter-institutional study. Breast Cancer Res Treat 148:511-523

21. Tőkés T, Tőkés AM, Szentmártoni G, Kiszner G, Madaras L, Kulka $\mathrm{J}$ et al (2016) Expression of cell cycle markers is predictive of the response to primary systemic therapy of locally advanced breast cancer. Virchows Archiv 468:675-686

22. Fasching PA, Heusinger K, Haeberle L, Niklos M, Hein A, Bayer $\mathrm{CM}$ et al (2011) Ki67, chemotherapy response, and prognosis in breast cancer patients receiving neoadjuvant treatment. BMC Cancer 11:486

23. Ács B, Zámbó V, Vízkeleti L, Szász AM, Madaras L, Gy S et al (2017) Ki-67 as a controversial predictive and prognostic marker in breast cancer patients treated with neoadjuvant chemotherapy. Diagn Pathol 12:20

24. Ahlin C, Zhou W, Holmqvist M, Holmberg L, Nilsson C, Jirstrom $\mathrm{K}$ et al (2009) Cyclin A is a proliferative marker with good prognostic value in node-negative breast cancer. Cancer Epidemiol Biomarkers Prev 18:2501-2506

25. Strand C, Ahlin C, Bendahl PO, Fjallskog ML, Hedenfalk I, Malmstrom $P$ et al (2012) Combination of the proliferation marker cyclin A, histological grade, and estrogen receptor status in a new variable with high prognostic impact in breast cancer. Breast Cancer Res Treat 131:33-40

26. Poikonen P, Sjostrom J, Amini RM, Villman K, Ahlgren J, Blomqvist C (2005) Cyclin A as a marker for prognosis and chemotherapy response in advanced breast cancer. Br J Cancer 93: $515-519$

27. Salgado R, Denkert C, Demaria S, Sirtaine N, Klauschen F, Pruneri $\mathrm{G}$ et al (2015) The evaluation of tumor-infiltrating lymphocytes (TILs) in breast cancer: recommendations by an International TILsWorking Group 2014. Ann Oncol 26:259-271

28. Cserni G, Francz M, Járay B, Kálmán E, Kovács I, Kulka J, Orosz Z, Udvarhelyi N, Vass L (2010) Pathological diagnostic, handling and histological findings in breast cancer. Magy Onkol 54:2017-2226

29. Pinder SE, Provenzano E, Earl H, Ellis IO (2007) Laboratory handling and histology reporting of breast specimens from patients who have received neoadjuvant chemotherapy. Histopathology 50:409-417

30. Jones RL, Lakhani SR, Ring AE, Ashley S, Walsh G, Smith IE (2006) Pathological complete response and residual DCIS following neoadjuvant chemotherapy for breast carcinoma. Br J Cancer 94:358-362 
31. Allred DC, Harvey JM, Berardo M, Clark GM (1998) Prognostic and predictive factors in breast cancer by immunohistochemical analysis. Mod Pathol 11:155-168

32. Wolff AC, Hammond ME, Schwartz JN, Hagerty KL, Allred DC, Cote RJ et al (2007) American Society of Clinical Oncology/ College of American Pathologists guideline recommendations for human epidermal growth factor receptor 2 testing in breast cancer. $\mathrm{J}$ Clin Oncol 25:118-145

33. Wolff AC, Hammond ME, Hicks DG, Dowsett M, McShane LM, Allison KH et al (2013) Recommendations for human epidermal growth factor receptor 2 testing in breast cancer: American Society of Clinical Oncology/College of American Pathologists clinical practice guideline update. J Clin Oncol 31:3997-4013

34. Dowsett M, Nielsen TO, A'Hern R, Bartlett J, Coombes RC, Cuzick $\mathrm{J}$ et al (2011) Assessment of Ki67 in breast cancer: recommendations from the International Ki67 in Breast Cancer working group. J Natl Cancer Inst 103:1656-1664

35. Pathmanathan N, Balleine RL (2013) Ki67 and proliferation in breast cancer. J Clin Pathol 66:512-516

36. Ali HR, Dawson SJ, Blows FM, Provenzano E, Pharoah PD, Caldas C (2012) Aurora kinase A outperforms Ki67 as a prognostic marker in ER-positive breast cancer. Br J Cancer 106:1798-1806

37. Wiesner FG, Magener A, Fasching PA, Wesse J, Bani MR, Rauh C et al (2009) $\mathrm{Ki}-67$ as a prognostic molecular marker in routine clinical use in breast cancer patients. Breast 18:135-141

38. Haerslev T, Jacobsen GK, Zedeler K (1996) Correlation of growth fraction by Ki-67 and proliferating cell nuclear antigen (PCNA) immunohistochemistry with histopathological parameters and prognosis in primary breast carcinomas. Breast Cancer Res Treat 37:101-113

39. Baak JP, Gudlaugsson E, Skaland I, Guo LH, Klos J, Lende TH et al (2009) Proliferation is the strongest prognosticator in node-negative breast cancer: significance, error sources, alternatives and comparison with molecular prognostic markers. Breast Cancer Res Treat 115: 241-254

40. Ahlin C, Aaltonen K, Amini RM, Nevanlinna H, Fjallskog ML, Blomqvist C (2007) Ki67 and cyclin A as prognostic factors in early breast cancer. What are the optimal cut-off values? Histopathology 51:491-498

41. Trihia H, Murray S, Price K, Gelber RD, Golouh R, Goldhirsch A et al (2013) International Breast Cancer Study G. Ki-67 expression in breast carcinoma: its association with grading systems, clinical parameters, and other prognostic factors-a surrogate marker? Cancer 97:1321-1331

42. Cheang MC, Chia SK, Voduc D, Gao D, Leung S, Snider J et al (2009) Ki67 index, HER2 status, and prognosis of patients with luminal B breast cancer. J Natl Cancer Inst 101:736-750

43. Nishimura R, Osako T, Okumura Y, Hayashi M, Toyozumi Y, Arima N (2010) Ki-67 as a prognostic marker according to breast cancer subtype and a predictor of recurrence time in primary breast cancer. Exp Ther Med 1:747-754

44. Keam B, Im SA, Lee KH, Han SW, Oh DY, Kim JH et al (2011) Ki67 can be used for further classification of triple negative breast cancer into two subtypes with different response and prognosis. Breast Cancer Res 13:R22

45. Mrklic I, Capkun V, Pogorelic Z, Tomic S (2013) Prognostic value of Ki-67 proliferating index in triple negative breast carcinomas. Pathol Res Pract 209:296-301

46. Stanton SE, Disis ML (2016) Clinical significance of tumorinfiltrating lymphocytes in breast cancer. J Immunother Cancer 24:59

47. Chung YR, Kim HJ, Jang MH, Park SY (2017) Prognostic value of tumor infiltrating lymphocyte subsets in breast cancer depends on hormone receptor status. Breast Cancer Res Treat 161:409-420

Publisher's Note Springer Nature remains neutral with regard to jurisdictional claims in published maps and institutional affiliations. 